\title{
Degradação de pastagens na Região Amazônica: propriedades físicas do solo e crescimento de raízes ${ }^{(1)}$
}

\author{
Marcelo Marques Lopes Muller(2), Maria de Fátima Guimarães ${ }^{(3)}$, \\ Thierry Desjardins ${ }^{(4)}$ e Paulo Fernando da Silva Martins ${ }^{(5)}$
}

\begin{abstract}
Resumo - O objetivo deste trabalho foi avaliar: (i) a relação entre a degradação de pastagens de colonião manejadas com queima, e as modificações nas propriedades físicas e morfológicas de um Argissolo Vermelho-Amarelo da Amazônia; (ii) o crescimento radicular de pastagens com diferentes níveis de degradação; (iii) o potencial de recuperação de pastagens degradadas de colonião com a introdução de andropógon. Numa propriedade rural da Região de Marabá, PA, foram estudados quatro tipos de pastagem: pastagem produtiva de colonião (Panicum maximum Jacq.); pastagem de colonião em declínio produtivo; pastagem de colonião degradada (capoeira); pastagem de colonião degradada e recuperada com andropógon (Andropogon gayanus Kunth). Como referência das propriedades do solo antes do desmatamento, estudou-se, também, uma reserva de mata nativa. A queima das pastagens foi prática usual, e apesar disso, estas não foram adubadas. A degradação da pastagem diminuiu a cobertura do solo e o deixou exposto à chuva e ao pisoteio do gado, o que resultou em aumento da densidade do solo na camada superficial e diminuição do grau de floculação da argila e da porosidade total. A diminuição da produção da parte aérea na pastagem degradada foi acompanhada de diminuição do número de raízes no perfil do solo, e da concentração do sistema radicular próximo à superfície. O andropógon demonstrou bom potencial para recuperação das áreas de pastagens degradadas, na Região Amazônica.

Termos para indexação: Andropogon gayanus, Panicum maximum, queimada, propriedades físico-químicas do solo.
\end{abstract}

\section{Pasture degradation in the Amazon region: soil physical properties and root growth}

\begin{abstract}
The objective of this study was to evaluate: (i) the relation between the degradation of burned Guinea grass pastures and the modifications of some physical and morphological properties of an Amazonian Ultisol; (ii) the root growth of pastures in different degradation stages; and (iii) the potential of rehabilitation of degraded Guinea grass pastures by introducing Gamba grass. On a farm at the eastern Amazon, region of Marabá, PA, Brazil, four pasture types were studied: productive Guinea grass (Panicum maximum Jacq.) pasture; Guinea grass pasture on yield decline; degraded Guinea grass pasture (fallow), and degraded Guinea grass pasture recovered with Gamba grass (Andropogon gayanus Kunth). As reference of the soil original characteristics before clearing, a native forest area was also studied. Burning was an usual practice; moreover, the pastures did not receive fertilizers. Pasture degradation decreased soil covering and exposed the soil surface to the direct impact of rain drops and cattle compaction, what resulted in soil bulk density increase in the superficial layer and decrease in clay flocculation and soil total porosity. Forage yield decline on degraded pasture was accompanied by a decrease on the number of roots on the soil profile, and there was a concentration of the root system close to the surface. Andropogon gayanus showed good potential for the rehabilitation of degraded pastures on the Amazon Region.
\end{abstract}

Index terms: Andropogon gayanus, Panicum maximum, burning, soil chemicophysical properties.

(1) Aceito para publicação em 22 de janeiro de 2001.

Extraído da Dissertação de Mestrado apresentada pelo primeiro autor à Universidade Estadual de Londrina (UEL), Londrina, PR.

Parcialmente financiado pela Capes.

(2) Universidade Estadual Paulista, Faculdade de Ciências Agronômicas, Caixa Postal 237, CEP 18603-970 Botucatu, SP E-mail: mmuller@fca.unesp.br
(3)UEL, Dep. de Agronomia, Caixa Postal 6001, CEP 86051-990 Londrina, PR. E-mail: mfatima@uel.br

(4)Institut Français de Recherche Scientifique pour le Développment en Coopération, Avenue Varagnat-32, 93143, Bondy, France. E-mail: Thierry.Desjardins@bondy.ird.fr

(5)Faculdade de Ciências Agrárias do Pará, Núcleo de Estudos Integrados sobre Agricultura Familiar, Caixa Postal 5036, CEP 66601-970 Belém, PA. E-mail: pmartins@nautilus.com.br 


\section{Introdução}

A queda na produtividade agrícola poucos anos após o desmatamento na Região Amazônica tem sido atribuída às pequenas reservas de nutrientes no solo, à toxicidade de $\mathrm{Al}$ e à fixação do $\mathrm{P}$, bem como à redução da porosidade total e da infiltração de água, e à degradação da estrutura do solo (Teixeira et al., 1996). Assim sendo, as atividades de exploração nos solos dessa região devem ser cuidadosamente planejadas, e as práticas de conservação do solo devem ser aplicadas desde o início do uso, para preservar o potencial produtivo do solo para as gerações futuras.

Inevitavelmente, a conversão de florestas em áreas agrícolas altera o equilíbrio natural existente, modificando as propriedades do solo. Anjos et al. (1994) compararam propriedades físicas de quatro solos sob mata nativa e sob cultivo em diferentes sistemas de manejo, e constataram que houve degradação da estrutura do solo cultivado, comprovada pelo aumento da densidade do solo, diminuição da porosidade total e diminuição da taxa de infiltração da água.

Cuidados no desmatamento podem reduzir o grau de degradação do solo inicialmente. Na Amazônia peruana, Seubert et al. (1977) observaram que o desmatamento da floresta com "bulldozers", feito por agricultores mais capitalizados, foi mais agressivo que o tradicional corte manual das árvores, feito por pequenos agricultores, e isto resultou em severa compactação e diminuição da infiltração de água no solo.

Além da baixa fertilidade natural dos solos e das alterações de suas propriedades físicas quando do desmatamento, grande parte das pastagens na Amazônia sofrem os efeitos de queimas freqüentes. Segundo Santos et al. (1992), entre as diversas razões apresentadas como justificativa para o uso da queima, destacam-se a renovação e a limpeza das pastagens a fim de aumentar a produção de forragem e melhorar sua palatabilidade. As queimas realizadas no fim do período seco ou no início do período chuvoso controlam o rebrote de plantas indesejáveis e aumentam a capacidade de pastejo.

Apesar de ser um método eficiente no controle da vegetação espontânea, a queima da pastagem pode ser muito danosa, pois além de consumir a vegeta- ção e deixar o solo descoberto, favorece a erosão, afeta os microorganismos do solo e elimina insetos inimigos naturais de pragas (Arruda, 1988). Costa (1982) constatou que após a queima de uma pastagem de colonião havia um maior perfilhamento da gramínea nos primeiros 30 dias, mas a recuperação da cobertura vegetal nunca era completa.

Embora as queimas de limpeza tenham sido alvo de muitos estudos, a maioria das pesquisas têm tratado de efeitos sobre o ambiente externo ao solo, ignorando os efeitos a longo prazo de queimas periódicas sobre as propriedades físicas e químicas do solo. Schacht et al. (1996), em estudos de mais de dez anos, concluíram que a queima anual da pastagem resultou na diminuição da taxa de infiltração de água, e que a densidade do solo foi maior nos tratamentos com queima anual do que com queima a cada quatro anos.

Carter \& Steed (1992), também ao longo de dez anos de estudo, verificaram que a queima de restos culturais, seguida ou não de preparo do solo, aumentou a densidade do solo e diminuiu a profundidade de umedecimento e o tempo necessário para alagamento do solo. Em outros estudos sobre o efeito da queima nas características físicas do solo, os resultados indicam reduções da macroporosidade e da água disponível (Araújo et al., 1994; Boyer \& Miller, 1994).

O objetivo deste estudo foi avaliar: (i) a relação entre a degradação de pastagens de colonião (Panicum maximum Jacq.) manejadas com queima, e as modificações de algumas propriedades físicas e morfológicas de um Argissolo Vermelho-Amarelo da Amazônia; (ii) o crescimento radicular de pastagens com diferentes níveis de degradação; (iii) o potencial de recuperação de pastagens degradadas de colonião com a plantação de andropógon (Andropogon gayanus Kunth).

\section{Material e Métodos}

O trabalho foi realizado em 1996, no Município de Jacundá (430' Sul e 49 $5^{\circ}$ ' Oeste), microrregião de Marabá, PA. O tipo climático local é Awi (tropical chuvoso), segundo classificação de Köppen, com temperatura média anual de $31,8^{\circ} \mathrm{C}$ e amplitude térmica inferior a $5^{\circ} \mathrm{C}$. $\mathrm{O}$ índice pluviométrico anual médio é de $2.000 \mathrm{~mm}$, com 
duas estações distintas: a chuvosa, entre os meses de dezembro e abril; e a menos chuvosa, entre maio e novembro, quando ocorrem os déficits (Cardoso et al., 1993). O solo estudado foi classificado como Podzólico Vermelho-Amarelo (Departamento Nacional da Produção Mineral, 1974), Argissolo Vermelho-Amarelo pelo novo Sistema Brasileiro de Classificação de Solos (Embrapa, 1999).

Foram estudadas quatro pastagens com diferentes níveis de degradação dentro de uma mesma propriedade rural: pastagem produtiva de colonião (Panicum maximum Jacq.) (P1); pastagem de colonião em declínio produtivo (P2); pastagem degradada de colonião (capoeira ) (P3); pastagem degradada de colonião recuperada com andropógon (Andropogon gayanus Kunth) (P4). A área relativa à $\mathrm{P} 1$ foi desmatada em 1982, cultivada com mandioca por dois anos, e com colonião por 12 anos; a relativa à $\mathrm{P} 2$ foi desmatada em 1978, fez-se um cultivo de arroz, seguido de colonião por 17 anos; a relativa à $\mathrm{P} 3$ foi desmatada em 1980, cultivada com mandioca por três anos, seguindo-se três anos de abandono, dois anos de mandioca, seis anos de colonião e dois anos de abandono (capoeira); e a relativa à $\mathrm{P} 4$ foi desmatada em 1979, fez-se um cultivo de arroz, seguido de colonião por onze anos, três anos de capoeira e dois anos de andropógon. Como referência das propriedades do solo antes do desmatamento, estudou-se, também, uma área de reserva de mata nativa $(\mathrm{Pn})$.

O grau crescente de degradação das pastagens de colonião foi avaliado pelo porte da forrageira, pela infestação de plantas invasoras, e pela cobertura do solo. A expressão "degradação da pastagem" foi utilizada neste estudo referindo-se ao decréscimo de produção de forragem pelas pastagens, as quais nunca receberam adubos ou corretivos e foram manejadas com queimas anuais na estação seca. As pastagens foram mantidas sem gado por algumas semanas antes das avaliações, conduzidas no fim da estação chuvosa, quando sua fitomassa é maior.

A declividade do terreno nas áreas escolhidas variava de $0-3 \%$, sendo abertas duas trincheiras em cada área, distanciadas por $30 \mathrm{~m}$ e com largura suficiente para expor as raízes de duas touceiras em cada trincheira. Procedeu-se, então, ao estudo do perfil radicular (Böhm, 1979), pela contagem das raízes expostas em perfil com telas de $50 \mathrm{~cm}$ x $50 \mathrm{~cm}$ (quadrícula de $5 \mathrm{~cm} \times 5 \mathrm{~cm}$ ), resultando em quatro repetições. Em seguida, realizou-se o estudo de perfil cultural (Tavares Filho et al., 1999), e, a partir dos dois perfis descritos em cada área, traçou-se um perfil característico. De cada perfil caracterizado foram coletadas três amostras indeformadas (anéis volumétricos) e uma amostra deformada composta (quatro subamostras) em cada camada.

As amostras indeformadas foram submetidas ao aparelho extrator de Richards (Embrapa, 1997) para determi- nação do teor de água do solo na tensão de $0,006 \mathrm{MPa}$, considerando-se o volume de água retida nesta tensão como sendo a microporosidade (Jorge \& Prado, 1988). A densidade do solo foi determinada pelo método do anel volumétrico (Embrapa, 1997).

Nas amostras deformadas, determinaram-se a densidade de partículas (método do balão volumétrico), o teor de matéria orgânica, a granulometria (método do densímetro) e a argila dispersa em água. $\mathrm{O}$ grau de floculação da argila foi calculado por meio da fórmula:

$\mathrm{GF}(\%)=100(\mathrm{AT}-\mathrm{ADA}) / \mathrm{AT}$,

onde AT é o teor de argila, e ADA, o teor de argila dispersa em água. A porosidade total do solo foi calculada por meio da fórmula:

PT $(\%)=100[1-(\mathrm{Ds} / \mathrm{Dp})]$,

onde Dp é a densidade de partículas $\left(\mathrm{Mg} \mathrm{m}^{-3}\right)$ e Ds é a densidade do solo $\left(\mathrm{Mg} \mathrm{m}^{-3}\right)$ (Embrapa, 1997).

\section{Resultados e Discussão}

Em relação ao perfil cultural, encontrou-se, em todas as áreas a seguinte seqüência de camadas a partir da superfície do solo: Livre (L); Contínuo $\Delta \mu$ $(\mathrm{C} \Delta \mu)$ e Contínuo $\Delta \mu / \mu(\mathrm{C} \Delta \mu / \mu)$. Tal nomenclatura indica o modo de arranjamento das unidades estruturais e seu estado interno. A estrutura L é composta de agregados livres e terra fina. A estrutura $C \Delta \mu$ se apresenta como um contínuo, sem que se possa individualizar visualmente torrões, havendo predomínio de porosidade de empilhamento de pequenos agregados, mas com porções sem porosidade visível a olho nu. A estrutura $\mathrm{C} \Delta \mu / \mu$ apresenta características semelhantes às do $\mathrm{C} \Delta \mu$, porém a porosidade visível é maior.

Sobre a superfície do solo havia uma camada uniforme de liteira com $8 \mathrm{~cm}$ de espessura na área $\mathrm{Pn}$, e com $2 \mathrm{~cm}$ nas pastagens $\mathrm{P} 1$ e $\mathrm{P} 4$. Na pastagem P2 essa espessura diminuiu para $1 \mathrm{~cm}$ e apareceram áreas de solo descoberto. Na P3 a espessura diminuiu para cerca de $0,5 \mathrm{~cm}$, e houve grande aumento das áreas de solo descoberto.

A camada $L$ apresentou espessura de $3 \mathrm{~cm}$ na área Pn, com um emaranhado de raízes unindo a massa de pequenos agregados. Nas pastagens P1, P2 e P4, essa camada se apresentou como um tapete de raízes finas, com pouco solo e espessura de $5 \mathrm{~cm}$. Na pastagem P3 a espessura dessa camada foi de $3 \mathrm{~cm}$, sendo observada uma fina camada de selamento superficial de cerca de $1 \mathrm{~cm}$, acima dela, principalmente nas áreas de solo descoberto. 
Esses resultados demonstram que houve diminuição da cobertura do solo pela liteira na seqüência P1 $>$ P2 $>$ P3, em razão da diminuição da fitomassa da forrageira com o declínio produtivo da pastagem, deixando o solo mais exposto ao impacto das gotas de chuva. Esse, segundo Derpsch et al. (1991), é o início do processo erosivo, e pode provocar selamento superficial e diminuição da infiltração e do armazenamento de água, intensificando o processo de erosão. Assim, a diminuição da espessura da camada L na pastagem $\mathrm{P} 3$ pode ser devida tanto à erosão quanto à compactação, uma vez que o solo descoberto também sofre compactação superficial pelo pisoteio do gado. Já na pastagem P4, a recuperação com o andropógon proporcionou uma boa cobertura do solo, a qual levou ao restabelecimento da camada L, com características estruturais mais similares a P1 que a P3.

A camada $\mathrm{C} \Delta \mu$ apresentou cavidades biológicas e empilhamento de agregados arredondados, com presença ou sinais de atividade de minhocas e formi- gas, que junto com as raízes construíram, em parte, o arranjamento dessa camada. Observou-se mosqueado ocre na matriz amarela, denotando excesso de água em alguns períodos do ano. Na camada $\mathrm{C} \Delta \mu / \mu$, a porosidade predominante também era de empilhamento de agregados arredondados, porém era maior e melhor distribuída. Nos primeiros centímetros dessa camada apareceram cascalhos e calhaus, os quais se tornaram muito abundantes a partir de $45 \mathrm{~cm}$. Nestas duas últimas camadas $(\mathrm{C} \Delta \mu \mathrm{e}$ $\mathrm{C} \Delta \mu / \mu$ ), não foram encontradas diferenças entre as pastagens, e tampouco observaram-se restrições ao enraizamento. Assim, o estudo do perfil cultural permitiu verificar que as modificações morfológicas do solo ocorreram somente na camada superficial (L).

Com o aumento da profundidade do solo, houve aumento no teor de argila e diminuição no de areia, o que está em concordância com a identificação do solo como sendo podzólico (Departamento Nacional da Produção Mineral, 1974) (Tabela 1). Os teores de matéria orgânica (MO) foram maiores na área Pn, e

Tabela 1. Granulometria, matéria orgânica, argila dispersa em água e grau de floculação da argila em área de mata nativa e em pastagens da Região Amazônica.

\begin{tabular}{|c|c|c|c|c|c|c|c|}
\hline Perfil cultural $^{(1)}$ & $\begin{array}{c}\text { Camada } \\
(\mathrm{cm})\end{array}$ & Areia & Silte & Argila & $\begin{array}{c}\text { Matéria } \\
\text { orgânica }\end{array}$ & $\begin{array}{c}\text { Argila } \\
\text { dispersa }\end{array}$ & $\begin{array}{c}\text { Grau de } \\
\text { floculação } \\
(\%)\end{array}$ \\
\hline & & \multicolumn{6}{|c|}{ Mata nativa } \\
\hline Livre & $0-3$ & 740 & 140 & 120 & 51 & 30 & 75 \\
\hline Contínuo $\Delta \mu$ & $3-12$ & 710 & 150 & 140 & 28 & 60 & 57 \\
\hline Contínuo $\Delta \mu / \mu$ & $12-48$ & 670 & 150 & 180 & 17 & 100 & 44 \\
\hline \multicolumn{8}{|c|}{ Pastagem produtiva de colonião } \\
\hline Livre & $0-5$ & 770 & 90 & 140 & 31 & 30 & 79 \\
\hline Contínuo $\Delta \mu$ & $5-25$ & 680 & 80 & 240 & 14 & 130 & 46 \\
\hline Contínuo $\Delta \mu / \mu$ & $25-48$ & 580 & 80 & 340 & 10 & 230 & 32 \\
\hline & & \multicolumn{6}{|c|}{ Pastagem de colonião em declínio produtivo } \\
\hline Livre & $0-5$ & 790 & 110 & 100 & 33 & 30 & 70 \\
\hline Contínuo $\Delta \mu$ & $5-25$ & 680 & 100 & 220 & 14 & 130 & 41 \\
\hline Contínuo $\Delta \mu / \mu$ & $25-44$ & 630 & 90 & 280 & 11 & 160 & 43 \\
\hline & & \multicolumn{6}{|c|}{ Pastagem degradada de colonião } \\
\hline Livre & $0-3$ & 710 & 90 & 200 & 30 & 80 & 60 \\
\hline Contínuo $\Delta \mu$ & $3-28$ & 630 & 90 & 280 & 16 & 160 & 43 \\
\hline Contínuo $\Delta \mu / \mu$ & $28-48$ & 580 & 100 & 320 & 8 & 200 & 38 \\
\hline & & \multicolumn{6}{|c|}{ Pastagem recuperada com andropógon } \\
\hline Livre & $0-5$ & 780 & 80 & 140 & 27 & 30 & 79 \\
\hline Contínuo $\Delta \mu$ & $5-25$ & 690 & 130 & 180 & 18 & 60 & 67 \\
\hline Contínuo $\Delta \mu / \mu$ & $25-45$ & 720 & 20 & 260 & 9 & 80 & 69 \\
\hline
\end{tabular}

${ }^{(1)} \Delta \mu$ : predomínio de porosidade de empilhamento de pequenos agregados, mas com porções sem porosidade visível a olho nu; $\Delta \mu / \mu$ apresenta características semelhantes às do $\Delta \mu$, porém a porosidade visível é maior. 
não houve diferenças importantes no teor de $\mathrm{MO}$ entre as pastagens em nenhuma das três camadas.

O aumento do teor de argila (AT) em profundidade foi acompanhado pelo aumento do teor de argila dispersa em água (AD) e pela diminuição do grau de floculação (GF), e houve boa correlação entre eles (Figura 1). Já a MO não apresentou boa correlação nem com a AD nem com o GF (Figura 2). Desta forma, o GF, que é um dos indicativos da estabilidade de agregados e da erodibilidade do solo, neste caso, foi mais influenciado pelo teor de argila do que pelo teor de matéria orgânica, o qual, normalmente, é reportado como importante agente na estabilização da estrutura do solo (Chaney \& Swift, 1984).

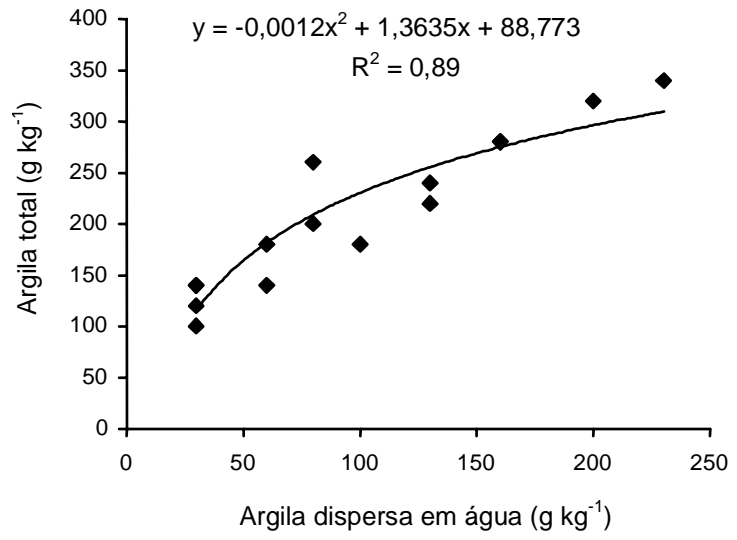

Comparando-se os dados de uma mesma camada nas diferentes áreas, os teores de AT e AD da camada $\mathrm{L}$ foram maiores na pastagem $\mathrm{P} 3$ que nas demais áreas, e nas camadas $\mathrm{C} \Delta \mu$ e $\mathrm{C} \Delta \mu / \mu$ esses teores foram menores nas áreas Pn e P4. Por outro lado, o GF apresentou comportamento inverso para as mesmas situações, o que confirma as correlações examinadas.

Os valores para o GF na camada $\mathrm{L}$ foram decrescentes na seqüência $\mathrm{P} 1>\mathrm{P} 2>\mathrm{P}$ 3, o que coincide com a diminuição da cobertura do solo pela liteira e com o aumento da degradação da pastagem, demonstrando, assim, que o solo foi sensível à diminuição da cobertura. Nas camadas $C \Delta \mu$ e $C \Delta \mu / \mu$, em que não há influência física da cobertura, o GF foi maior nas

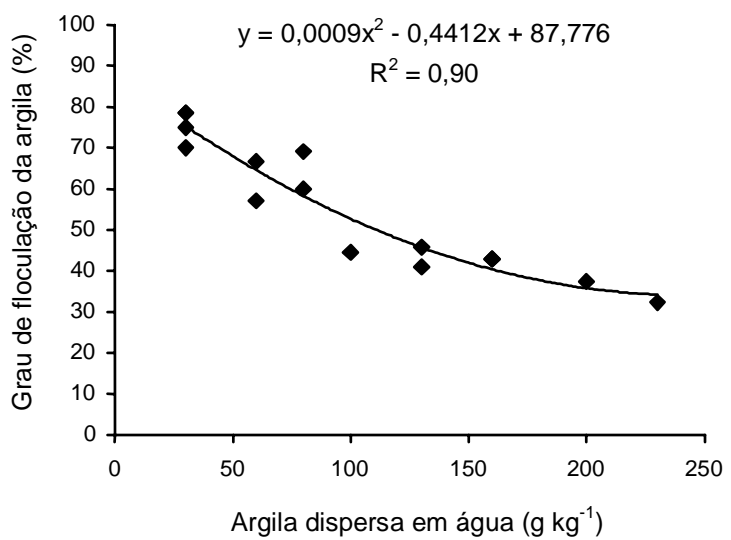

Figura 1. Argila total e grau de floculação em razão da argila dispersa em água em Argissolo Vermelho-Amarelo da Amazônia.
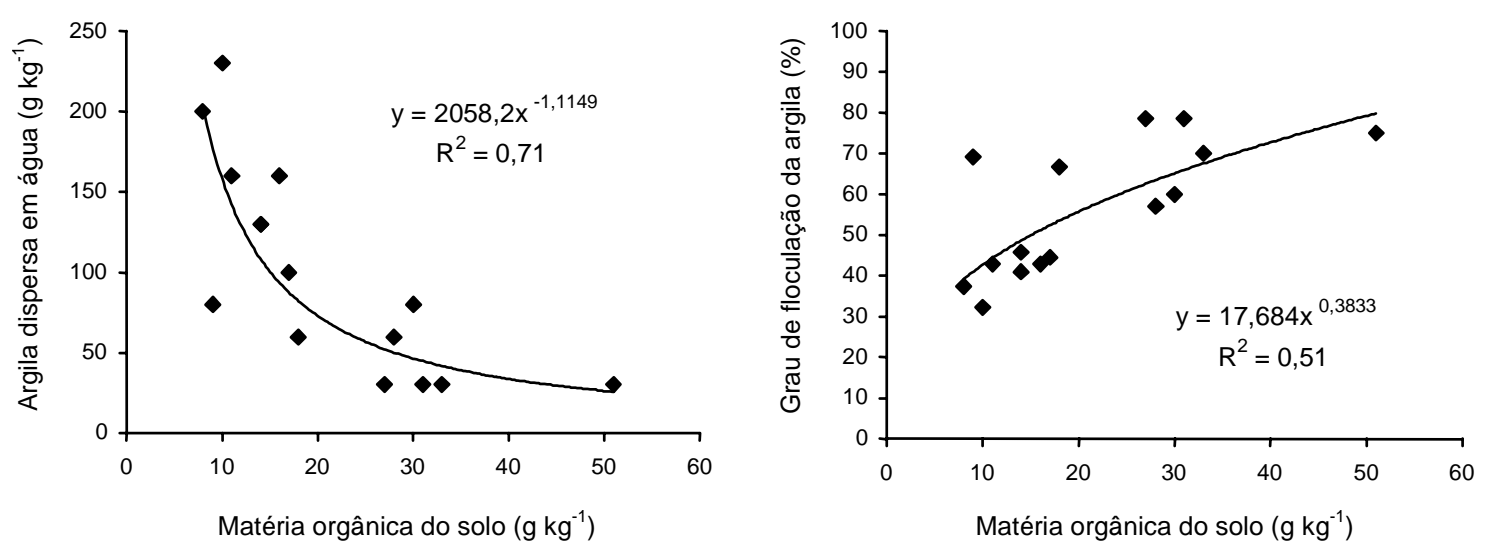

Figura 2. Argila dispersa em água e grau de floculação em razão da matéria orgânica em Argissolo Vermelho-Amarelo da Amazônia. 
áreas Pn e P4. Em Pn, a explicação para este fato pode estar relacionada ao maior teor de MO. No caso da pastagem $\mathrm{P} 4$, a diferença de comportamento em relação a P1, P2 e P3 não pode ser explicada pelo teor de $\mathrm{MO}$, o qual foi semelhante entre todas as pastagens, mas talvez pela natureza diferente dos compostos orgânicos das raízes (Pojasok \& Kay, 1990; Dinel et al., 1991), já que as espécies são diferentes.

A densidade do solo (Ds) foi menor no solo sob mata do que no solo cultivado com pastagem (Tabela 2), o que está de acordo com os resultados de Anjos et al. (1994). Nas pastagens, foi possível notar que a Ds aumentou da camada $\mathrm{L}$ para a camada $\mathrm{C} \Delta \mu$, por causa de maiores teores de argila e de menores teores de MO nessa última camada. Entre as camadas $\mathrm{C} \Delta \mu$ e $\mathrm{C} \Delta \mu / \mu$, as diferenças foram menores, embora a camada $\mathrm{C} \Delta \mu / \mu$ tenha apresentado valores ligeiramente maiores de PT e menores de Ds na maioria das áreas. Na área Pn, a Ds na camada L foi menor que nas pastagens, resultado da boa cobertura do solo pela mata e pela espessa camada de liteira, bem como do teor elevado de matéria orgânica e do alto grau de agregação observado no perfil cultural.

Quanto às pastagens, P3 apresentou aumento nítido de Ds na camada superficial, resultado da diminuição da cobertura do solo e aumento da degradação da pastagem, em razão do tempo de cultivo e do número de queimas, o que está de acordo com os resultados de Carter \& Steed (1992), Boyer \& Miller (1994) e Schacht et al. (1996). Nas outras pastagens, os valores de Ds podem ser considerados semelhantes (Tabela 2).

A densidade do solo mostrou boa correlação com a porosidade total e com a macroporosidade (Figura 3). Quando a Ds aumentou, a PT e a macroporosidade diminuíram. A PT decresceu em profundidade e entre os modos de utilização $(\mathrm{Pn}>\mathrm{P} 4>\mathrm{P} 1>\mathrm{P} 2>\mathrm{P} 3)$.

Tabela 2. Densidade de partícula (Dp), densidade de solo (Ds) e porosidade do solo em área de mata nativa e em pastagens da Região Amazônica ${ }^{(1)}$.

\begin{tabular}{|c|c|c|c|c|c|c|}
\hline \multirow[t]{3}{*}{ Perfil cultural $^{(2)}$} & \multirow{3}{*}{$\begin{array}{c}\text { Camada } \\
(\mathrm{cm})\end{array}$} & \multirow{3}{*}{$\mathrm{Dp}$} & \multirow{2}{*}{ Ds } & \multicolumn{3}{|c|}{ Porosidade } \\
\hline & & & & Micro & Macro & Total \\
\hline & & & & \multicolumn{3}{|c|}{-} \\
\hline & & & & Mata $n$ & & \\
\hline Livre & $0-3$ & 2,4 & 1,01 & 0,269 & 0,309 & 0,578 \\
\hline Contínuo $\Delta \mu$ & $3-12$ & 2,5 & 1,39 & 0,222 & 0,222 & 0,444 \\
\hline \multirow[t]{2}{*}{ Contínuo $\Delta \mu / \mu$} & $12-48$ & 2,4 & 1,33 & 0,213 & 0,232 & 0,445 \\
\hline & & \multicolumn{5}{|c|}{ Pastagem produtiva de colonião } \\
\hline Livre & $0-5$ & 2,6 & 1,22 & 0,272 & 0,263 & 0,533 \\
\hline Contínuo $\Delta \mu$ & $5-25$ & 2,5 & 1,52 & 0,243 & 0,149 & 0,392 \\
\hline \multirow[t]{2}{*}{ Contínuo $\Delta \mu / \mu$} & $25-48$ & 2,6 & 1,39 & 0,268 & 0,201 & 0,469 \\
\hline & & \multicolumn{5}{|c|}{ Pastagem de colonião em declínio produtivo } \\
\hline Livre & $0-5$ & 2,5 & 1,27 & 0,284 & 0,205 & 0,489 \\
\hline Contínuo $\Delta \mu$ & $5-25$ & 2,6 & 1,61 & 0,209 & 0,172 & 0,381 \\
\hline \multirow[t]{2}{*}{ Contínuo $\Delta \mu / \mu$} & $25-44$ & 2,6 & 1,55 & 0,258 & 0,149 & 0,407 \\
\hline & & \multicolumn{5}{|c|}{ Pastagem degradada de colonião (capoeira) } \\
\hline Livre & $0-3$ & 2,5 & 1,40 & 0,225 & 0,216 & 0,441 \\
\hline Contínuo $\Delta \mu$ & $3-28$ & 2,6 & 1,52 & 0,264 & 0,150 & 0,414 \\
\hline \multirow[t]{2}{*}{ Contínuo $\Delta \mu / \mu$} & $28-48$ & 2,6 & 1,47 & 0,279 & 0,158 & 0,436 \\
\hline & & \multicolumn{5}{|c|}{ Pastagem recuperada com andropógon } \\
\hline Livre & $0-5$ & 2,6 & 1,25 & 0,216 & 0,304 & 0,520 \\
\hline Contínuo $\Delta \mu$ & $5-25$ & 2,6 & 1,49 & 0,253 & 0,174 & 0,427 \\
\hline Contínuo $\Delta \mu / \mu$ & $25-45$ & 2,4 & 1,49 & 0,233 & 0,147 & 0,380 \\
\hline
\end{tabular}


Quanto à microporosidade, ocorreu uma compensação, pois a diminuição da PT ocorre, inicialmente, transformando poros grandes em pequenos, com tendência a aumentar a água retida pelo solo. Isso fez com que a macroporosidade tivesse valores ainda menores nas pastagens mais degradadas.

De modo geral, em condições naturais ou sob pastagens com menor grau de degradação (Pn, P1 e P2), a porosidade total foi maior na camada $\mathrm{L}$ do que nas camadas $\mathrm{C} \Delta \mu$ e $\mathrm{C} \Delta \mu / \mu$. Entretanto, com a degradação da pastagem, a porosidade total da camada $L$ foi reduzida, tornando-se igual à encontrada nas camadas subsuperficiais (P3), o que resulta em menor capacidade de infiltração de água no solo e maior exposição à erosão. Neste aspecto, a pastagem de andropógon (P4) demonstrou recuperar a estrutura do solo nesta camada, pois promoveu um aumento da porosidade total, melhor agregação do solo e maior grau de floculação da argila.

O crescimento radicular foi diferente entre as pastagens, tanto no que se refere ao número total de raízes como à distribuição relativa em profundidade (Tabela 3), resultado das características do solo e das diferentes espécies de forrageiras.

Comparando-se P1 e P2, cujos dados se referem quase exclusivamente a raízes de colonião, observouse que o número de raízes nas camadas de $0-10$, 10-20, 20-30, 30-40 e 40-50 cm foi menor em P2 do que em $\mathrm{P} 1$. Quanto à distribuição relativa das raízes nas diferentes camadas, P2 apresentou maior porcentual de raízes na camada de $0-10 \mathrm{~cm}$ e menores porcentuais nas camadas de 10-20, 30-40 e
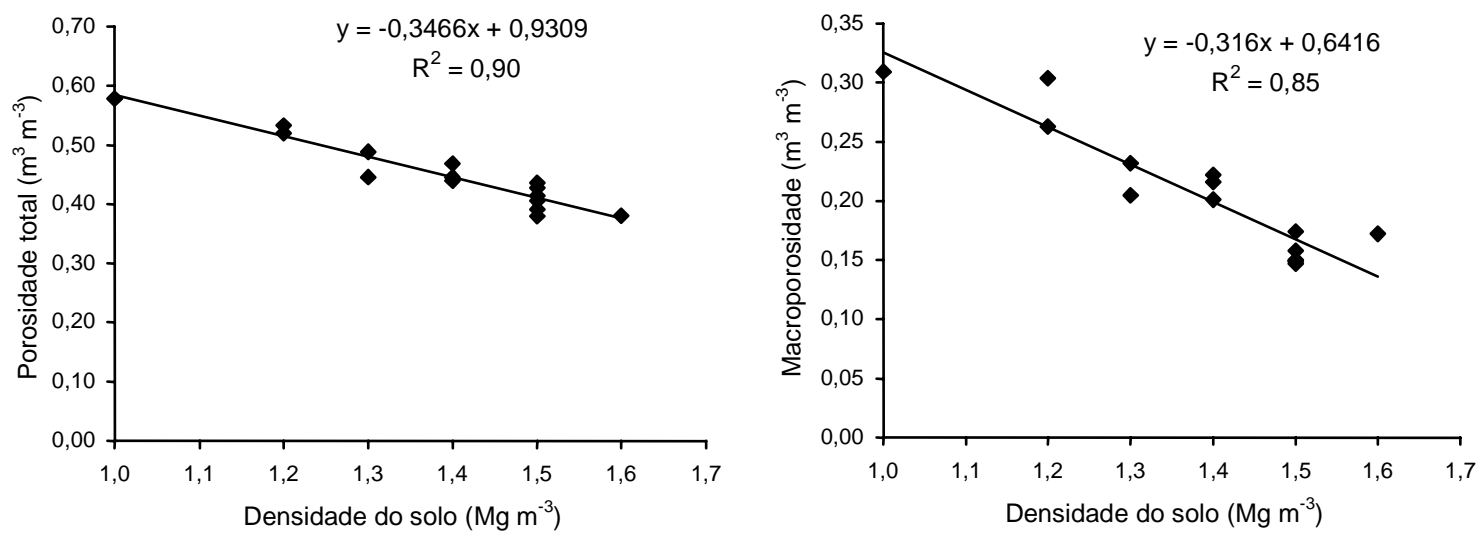

Figura 3. Porosidade total e macroporosidade em razão da densidade do solo em Argissolo Vermelho-Amarelo da Amazônia.

Tabela 3. Distribuição de raízes no perfil do solo em pastagens da Região Amazônica (média de quatro repetições) ${ }^{(1)}$.

\begin{tabular}{|c|c|c|c|c|c|c|c|c|}
\hline \multirow{2}{*}{$\begin{array}{c}\text { Camada } \\
\text { de solo } \\
(\mathrm{cm})\end{array}$} & \multicolumn{2}{|c|}{$\begin{array}{l}\text { Pastagem produtiva de } \\
\text { colonião }\end{array}$} & \multicolumn{2}{|c|}{$\begin{array}{l}\text { Pastagem de colonião } \\
\text { em declínio produtivo }\end{array}$} & \multicolumn{2}{|c|}{$\begin{array}{l}\text { Pastagem degradada } \\
\text { de colonião (capoeira) }\end{array}$} & \multicolumn{2}{|c|}{$\begin{array}{c}\text { Pastagem recuperada } \\
\text { com andropógon }\end{array}$} \\
\hline & Número & $\%$ & Número & $\%$ & Número & $\%$ & Número & $\%$ \\
\hline $0-10$ & 558 & 47 & 532 & 53 & 487 & 51 & 517 & 44 \\
\hline $10-20$ & 310 & 26 & 227 & 23 & 223 & 23 & 252 & 21 \\
\hline $20-30$ & 138 & 12 & 118 & 12 & 110 & 11 & 188 & 16 \\
\hline $30-40$ & 107 & 9 & 72 & 7 & 85 & 9 & 132 & 11 \\
\hline $40-50$ & 77 & 6 & 56 & 5 & 58 & 6 & 96 & 8 \\
\hline Total & 1.190 & 100 & 1.005 & 100 & 963 & 100 & 1.185 & 100 \\
\hline
\end{tabular}


40-50 cm, respectivamente, o que resultou em menor exploração do perfil do solo e maior exposição ao estresse hídrico nos meses de seca.

Este resultado indica que o declínio produtivo da parte aérea de colonião, observado visualmente durante a escolha das áreas para o estudo, foi acompanhado de redução do crescimento do sistema radicular. Humphreys \& Robinson (1966) constataram que a diminuição na produção da parte aérea de P. maximum trichoglume foi acompanhada de reduções no crescimento das raízes e na quantidade de carboidratos armazenados nas folhas e raízes, resultando na diminuição da capacidade das plantas em restabelecer o sistema radicular e gerar perfilhos após a estação das secas.

Na pastagem $\mathrm{P}$ 3, cujos dados do perfil radicular se referem a uma cobertura vegetal composta principalmente pela espécie voluntária Andropogon bicornis, bem como por colonião e outras voluntárias, o número de raízes nas camadas de 0 -10, 10-20 e 20-30 cm foi menor do que nas pastagens P1 e P2, indicando, assim, que as características físicas do solo nas camadas $L$ e $C \Delta \mu(0-28 \mathrm{~cm})$ não geraram boas condições para o crescimento radicular. $\mathrm{O}$ número total de raízes na pastagem $\mathrm{P} 3$ também foi menor que nas pastagens $\mathrm{P} 1$ e $\mathrm{P} 2$. Contudo, tanto o número como o porcentual de raízes nas camadas de 30-40 e 40-50 cm foram maiores na pastagem P3 que na P2. Isto pode representar o efeito das melhores condições de macro e microporosidade da camada $\mathrm{C} \Delta \mu / \mu$ $(28-48 \mathrm{~cm})$ na pastagem $\mathrm{P} 3$, ou a maior rusticidade da espécie $A$. bicornis em relação ao colonião, já que ela passou a compor a pastagem quando o potencial competitivo do colonião havia sido reduzido.

$\mathrm{O}$ número total de raízes na pastagem $\mathrm{P} 4$ foi maior que nas pastagens P3 e P2, e bastante próximo ao observado na pastagem $\mathrm{P} 1$, o que, somado ao bom desenvolvimento da parte aérea, comprova o bom estado desta pastagem. $\mathrm{O}$ número de raízes nas camadas de 0-10 e 10-20 cm também foram superados por aquele da $\mathrm{P} 1$, mas, nas camadas de 20-30, 30-40 e 40-50 cm, o número de raízes na pastagem $\mathrm{P} 4$ foi bem maior que nas outras pastagens, e não encontra explicação nas condições físicas do solo, já que na camada $\mathrm{C} \Delta \mu / \mu(25-45 \mathrm{~cm})$ desta pastagem os valores de porosidade são os menores entre todas as pastagens. Assim, este resultado se deve à maior rusti- cidade da espécie Andropogon gayanus, comprovada pela literatura (Jones, 1979; Silva et al., 1992; Mitja et al., 1998).

Nas áreas estudadas, a degradação da pastagem de colonião, percebida visualmente pela diminuição de produção de forragem, pela maior infestação de plantas invasoras e pela menor cobertura do solo, foi acompanhada de diminuição da porosidade total e conseqüente aumento da densidade do solo em sua camada superficial. Nesta camada, o grau de floculação da argila, que indica a estabilidade dos microagregados, diminuiu com o aumento da degradação da pastagem. Quanto ao crescimento radicular, a degradação da pastagem mostrou, também, estar relacionada a uma diminuição do número de raízes no perfil de solo e a uma concentração do sistema radicular nas camadas mais superficiais.

Assim, a diminuição do crescimento da parte aérea da pastagem - cuja causa inicial pode ser uma interação entre fatores amplamente discutidos em outros estudos na região, entre eles a baixa fertilidade do solo e o uso freqüente da queima - promove a diminuição da cobertura do solo, deixando-o exposto ao efeito compactante do pisoteio pelo gado e à dispersão dos agregados pelo impacto direto das gotas de chuva; e esta pode provocar selamento superficial, e junto com a compactação, diminuir a infiltração da água no solo e aumentar o escorrimento superficial e a erosão, gerando condições que também funcionarão como causa da degradação da pastagem.

Uma alternativa para recuperar essas pastagens degradadas pode ser o andropógon, espécie mais rústica que o colonião e que neste estudo mostrou-se capaz de crescer e desenvolver-se numa condição de solo onde o colonião já se havia degradado. Além disso, dois anos após a instalação do andropógon, o grau de floculação, a macroporosidade e a porosidade total do solo mostraram-se maiores que no solo das pastagens degradadas, e a densidade do solo foi menor na camada superficial, o que pode representar uma recuperação não só da pastagem mas também do solo.

\section{Conclusões}

1. A degradação da pastagem diminui a cobertura do solo, resultando em aumento da densidade do 
solo na camada superficial e em diminuição do grau de floculação da argila e da porosidade total.

2. A diminuição da produção da parte aérea na pastagem degradada foi acompanhada de diminuição do número de raízes no perfil do solo e de uma concentração do sistema radicular próximo à superfície.

3. O andropógon demonstrou bom potencial para recuperação das áreas de pastagens degradadas na região estudada.

\section{Referências}

ANJOS, J. T.; UBERTI, A. A. A.; VIZZOTO, V. T.; LEITE, G. B.; KRIEGER, M. Propriedades físicas em solos sob diferentes sistemas de manejo. Revista Brasileira de Ciência do Solo, Campinas, v. 18, p. 139-145, 1994.

ARAÚJO, Q. R. de; FIGUEIREDO, M. de S.; COSTA, L. M. da; LOURES, E. G.; REGAZZI, A. J.; FONTES, L. E. F.; CASALI, V. W. D. Efeito da queima e da percolação sobre a dinâmica de propriedades físicas de um Latossolo Vermelho-Amarelo, variação Una. Agrotropica, Itabuna, v. 6, p. 15-25, 1994.

ARRUDA, M. L. R. Estabelecimento e recuperação de pastagens no vale do Rio Doce. Informe Agropecuário, Belo Horizonte, v. 13, p. 23-25, 1988.

BÖHM, W. Methods of studying root system. Berlim: Springer, 1979. $188 \mathrm{p}$.

BOYER, W. D.; MILLER, J. H. Effect of burning and brush treatments on nutrient and soil physical properties in young longleaf pine stands. Forest Ecology and Management, Amsterdam, v. 70, p. 311-318, 1994

CARDOSO, A.; MARTINS, P. F. S.; VEIGA JÚNIOR, I. Solos de áreas ocupadas por pequenos agricultores em algumas localidades da microrregião de Marabá, Pará. In: SEMINÁRIO SOBRE AGRICULTURA FAMILIAR E DESENVOLVIMENTO RURAL NA AMAZÔNIA ORIENTAL, 1993, Marabá. Anais... Point à Pitre: Université des Antilles et de la Guyane, 1993. p. 101-123.

CARTER, M. R.; STEED, G. R. The effects of directdrilling and stubble retention on hydraulic properties at the surface of duplex soils in north-eastern Victoria. Australian Journal of Soil Research, Collingwood, v. 30, p. 505-516, 1992.

CHANEY, K.; SWIFT, R. S. The influence of organic matter on aggregate stability in some British soils. Journal of Soil Science, Oxford, v. 35, p. 223-230, 1984.
COSTA, B. M. da. Queima e roçagem em pastagem de capim-colonião (Panicum maximum Jacq.): seus efeitos no solo e nas plantas. Viçosa, MG: UFV, 1982. 122 p. Dissertação de Mestrado.

DEPARTAMENTO NACIONAL DA PRODUÇÃO MINERAL. Projeto RADAMBRASIL. Folha SB22 Araguaia e parte da folha SC22 Tocantins: geomorfologia e solos. Rio de Janeiro, 1974. Seção 3. (Levantamento de recursos naturais, 4 ).

DERPSCH, R.; ROTH, C. H.; SIDIRAS, N.; KÖPKE, U. Fundamentos do controle de erosão dos solos: bases do projeto. In:_ Controle da erosão no Paraná, Brasil: sistemas de cobertura do solo, plantio direto e preparo conservacionista do solo. Eschborn: Deutsche Gesellschaft für Technische Zusammen Arbeit (GTZ), 1991. p. 47-52.

DINEL, H.; MEHUYS, G. R.; LÉVESQUE, M. Influence of humic and fibric materials on the aggregation and aggregate stability of a lacustrine silty clay. Soil Science, Baltimore, v. 151, p. 146-158, 1991.

EMBRAPA. Centro Nacional de Pesquisa de Solos (Rio de Janeiro, RJ). Manual de métodos de análise do solo. 2. ed. Rio de Janeiro, 1997. 212 p.

EMBRAPA. Centro Nacional de Pesquisa de Solos (Rio de Janeiro, RJ). Sistema brasileiro de classificação de solos. Rio de Janeiro, 1999. 412 p.

HUMPHREYS, L. R.; ROBINSON, A. R. Interrelations of leaf area and nonstructural carbohydrate status as determinants of the growth of subtropical grasses. In: INTERNATIONAL GRASSLAND CONGRESS, 1966, Helsinki. Proceedings... Helsinki: University of Helsinki, 1966. p. 113-116.

JONES, C. A. The potential of Andropogon gayanus Kunth in the Oxisol and Ultisol savannas of the Tropical America. Commonwealth Bureau of Pastures and Field Crops Bulletin, Wallingford, v. 49, p. 1-8, 1979.

JORGE, J. A.; PRADO, H. do. Porosidade, consistência e propriedades hídricas de três podzólicos vermelho-amarelos e uma terra roxa estruturada. Revista Brasileira de Ciência do Solo, Campinas, v. 12, p. 211-216, 1988.

MITJA, D.; LEAL FILHO, N.; TOPALL, O. Pour une réhabilitation des pâturages Amazoniens degrades: l'exemple d'Andropogon gayanus Kunth (Marabá, Pará, Brésil). Revue d'Ecologie: la Terre et la Vie, Paris, v. 53, p. 39-57, 1998.

POJASOK, T.; KAY, B. D. Effect of root exudates from corn and bromegrass on soil structural stability. Canadian Journal of Soil Science, Ottawa, v. 70, p. 351-362, 1990. 
SANTOS, D.; BAHIA, V. G.; TEIXEIRA, W. G. Queimadas e erosão do solo. Informe Agropecuário, Belo Horizonte, v. 16, p. 62-68, 1992.

SCHACHT, W. H.; STUBBENDIECK, T.; BRAGG T. B.; SMART, A. J.; DORAN, J. W. Soil quality response of reestablished grasslands to mowing and burning. Journal of Range Management, Denver, v. 49, p. 458-463, 1996.

SEUBERT, C. E.; SANCHEZ, P. A.; VALVERDE, C. Effects of land clearing methods on soil properties of an ultisol and crop performance in the Amazon jungle of Peru. Tropical Agriculture, St. Augustine, v. 54, p. 307-322, 1977.

SILVA, G. P.; NOVAIS, R. F.; NEVES, J. C. L.; BARROS, N. F. Respostas de espécies de gramíneas forrageiras a camadas compactadas de solo. Revista Ceres, Viçosa, MG, v. 39, p. 31-43, 1992.

TAVARES FILHO, J.; RALISCH, R.; GUIMARÃES, M. F.; MEDINA, C. C.; BALBINO, L. C.; NEVES, C. S. V. J. Método do perfil cultural para avaliações do estado físico de solos em condições tropicais. Revista Brasileira de Ciência do Solo, Campinas, v. 23, p. 393-399, 1999.

TEIXEIRA, W. G.; PEREIRA, E. G.; CRUZ, L. A.; BUENO, N. Influência do uso nas características físicoquímicas de um Latossolo Amarelo, textura muito argilosa, Manaus, AM. In: CONGRESSO LATINO-AMERICANO DE CIÊNCIA DO SOLO, 12., 1996, Águas de Lindóia. Anais... Campinas: Sociedade Brasileira de Ciência do Solo/Sociedade Latino-Americana de Ciência do Solo, 1996. 1 CD-ROM. 